\title{
Sexuality and Emergency Contraceptive Practice among Female Undergraduates in Lagos, Nigeria
}

\author{
Yusuf Abisowo Oshodi*, Fatimat Motunrayo Akinlusi, Akaninyene Akpan Uduosoro, \\ Joy Onyinyechi Agbara, Kabiru Afolarin Rabiu, Oluwarotimi Ireti Akinola
}

Department of Obstetrics and Gynecology, Lagos State University Teaching Hospital, Ikeja, Nigeria

Email: *yusufoshodi@gmail.com

How to cite this paper: Oshodi, Y.A., Akinlusi, F.M., Uduosoro, A.A., Agbara, J.O., Rabiu, K.A. and Akinola, O.I. (2020) Sexuality and Emergency Contraceptive Practice among Female Undergraduates in Lagos, Nigeria. Open Journal of Obstetrics and Gynecology, 10, 836-854.

https://doi.org/10.4236/ojog.2020.1060078

Received: May 15, 2020

Accepted: June 27, 2020

Published: June 30, 2020

Copyright $\odot 2020$ by author(s) and Scientific Research Publishing Inc. This work is licensed under the Creative Commons Attribution International License (CC BY 4.0).

http://creativecommons.org/licenses/by/4.0/

(c) (i) Open Access

\begin{abstract}
Background: Young people, especially those in tertiary institutions are vulnerable to unplanned and unprotected sexual intercourse which predisposes them to unintended pregnancies and subsequently unsafe abortions. One of the key interventions for reduction of unwanted pregnancies and unsafe abortions is effective use of emergency contraceptives. Objectives: To assess the sexuality, perception, attitude towards and determinants of usage of emergency contraception among female undergraduates in Lagos, Nigeria. Methods: Cross-sectional survey conducted in June 2016 among 805 female students of the Lagos State University. Data were collected through structured self-administered questionnaire by obtaining information on demography, sexual and contraceptive history, perception, attitude towards and use of emergency contraceptives. Data obtained were analyzed using SPSS version 16. Chi-square and logistic regression models were applied to variables to test for significance that predicts the use of emergency contraceptives. Results: Of the 725 (90\%) completed questionnaires, $334(46 \%)$ of the respondents were sexually active with 115 (34\%) having previous history of pregnancy. Eighty-two percent of those pregnancies were unintended. Eighty-eight percent of those with unintended pregnancy had them terminated by induced abortions, $54 \%$ of which was carried out by untrained persons. Only $29 \%$ of those who had unprotected sexual intercourse used emergency contraceptives. Lack of knowledge and promotion of sexual promiscuity were identified as the main reasons for not using emergency contraceptives. Previous use of contraceptives, married status, increasing age and year of study were positive predictors for the use of emergency contraceptives while poor knowledge was a significant predictor of non-use. Conclusion: There was poor knowledge and low utilization of emergency contraceptives among respondents. Information on
\end{abstract}


contraceptives should be introduced in secondary schools and in general studies courses in tertiary institutions while parents and caregivers should discuss issues relating to sex and contraceptives with adolescents.

\section{Keywords}

Sexuality, Unprotected Intercourse, Unintended Pregnancy, Emergency Contraceptives Practice

\section{Introduction}

The incidence of unwanted pregnancies leading to unsafe abortion, particularly among adolescents is very high [1] [2]. Unsafe abortion is a major public health issue because of its contribution to high rates of maternal morbidity and mortality [3]. Globally, about 46 million unwanted pregnancies are terminated every year. The annual incidence of induced abortions in Africa rose from 5.6 million to 6.4 million between 2003 and 2008 due largely to increase in the number of women of reproductive age [4] [5]. The overall incidence of induced abortion in Nigeria is 25 per 1000 women of reproductive age per year [3] [6] [7]. Approximately 610,000 abortions are performed annually in Nigeria, of which about $60 \%$ may be unsafe, thereby contributing about $20 \%$ to overall maternal deaths of $27.4 \%$ in Nigeria [8], 34.6\% in Cameroon [9] and 21\% in Uganda [10].

Studies have also shown that young people, particularly those in tertiary institutions are vulnerable to unplanned and unprotected sexual intercourse which predisposes them to unintended pregnancies and subsequently leading to the procurement of unsafe abortions [3] [7]. The increased proportion of induced and unsafe abortion in African countries including Nigeria can be linked to declining age of sexual debut, increasing rate of sexual activities among adolescents and low use of contraceptives among married and single women [8]. The consequences of unprotected sexual intercourse, such as unwanted pregnancies, unsafe abortion and its sequelae, cost of termination of pregnancies, emotional and long term reproductive failure can be prevented or reduced drastically by access to and use of contraceptive services, especially emergency contraceptives [3] [4]. The World Health Organization (WHO) estimated that in Africa in $2008,14 \%$ of maternal deaths $(29,000)$ were due to unsafe abortion. About 1.7 million women in the region were hospitalized annually for complications arising from unsafe abortion [3].

Emergency contraceptive is an intervention to prevent pregnancy following unplanned, unprotected sexual intercourse, unlike the regular methods of contraception that are taken before sexual intercourse. It has the potential, as the last resort, to prevent unwanted pregnancy and therefore help reduce unsafe abortion rate; a desirable goal especially in a country like Nigeria where abortion law is restrictive. Studies as far back as 1990 on termination of pregnancy have identified emergency contraceptive as one of the key interventions to prevent 
unwanted pregnancy in the United Kingdom [11]. However, use of the method is low, provision is patchy and knowledge is poor. Women are interested in preventing unintended pregnancies, hence further information and availability would help them achieve this. Knowledge of emergency contraception is crucial to its utilization [11].

Combined oral contraceptive pills (Yuzpe's) and levonorgestrel only pills (postinor) are the most common emergency contraceptive methods available in Nigeria; they are commonly available in pharmacies and can be obtained over the counter without prescription [12]. When emergency contraceptives are used within 72 hours after sexual intercourse, they have the capacity to prevent pregnancy by $75 \%-85 \%$ and as much as $99 \%$ with intra-uterine contraceptive device [13]. Unconventional technique of doubtful potential and efficacy are also commonly available in Nigeria. Teenage girls in Nigeria have been reported to use laxatives, quinine, menstrogen pills, and potash with unproven efficacies in prevention of unwanted pregnancy [14].

This study was designed to explore the sexuality, perception, attitude towards and utilization of emergency contraceptives among female undergraduate students in Lagos State University.

\section{Materials and Methods}

A descriptive cross-sectional study was carried out in June 2016 among Female non-medical undergraduate students of Lagos State University. The university has about 8000 female students. All the students reside off campus as there were no hostel facilities as at the time the study was conducted. Sample size was calculated using a simple proportion formula assuming the proportion of students who are aware of emergency contraceptives is $50 \%$, adding a non-response rate of $5 \%$ and multiplying by a design effect of 2 due to multi-stage nature of sampling method, the required sample size was 805 .

CALCULATION OF SAMPLE SIZE:

Step $1 n=t^{2} \times p(1-p) / m$

Description; $n=$ required sample size.

$t=$ confidence level at 95\% (standard value of 1.95).

$p=$ estimate $d$ prevalence of contraception in the project area.

$m=$ margin of error at $5 \%$ (standard value of 0.05 )

$$
n=1.96^{2} \times 0.5(1-0.5) / 0.0025=384
$$

Step 2 when this is multiply with the design effect of 2

$$
n \times 2=768
$$

Step 3 contingency the sample is increase by $5 \%$ to account for contingency such as non-response of recording

$$
n+(5 / 100 \times 768)=768+38.5=806
$$

Step 4 This is then further adjusted to the cluster of study. In this case, cluster of 7 (7 faculties) $=805$ (i.e. 115 per cluster). 


\section{RESPONDENTS SELECTION}

At first stage, seven faculties were randomly selected from the institution. At the second stage, seven departments were then randomly selected from these faculties where consenting individual female students had questionnaire administered to them consecutively (convenient non-probability sampling) in each of the departments. Ethical approval was obtained from the Health Research and Ethics Committee of the Lagos State University Teaching Hospital.

Data was collected using structured self-administered questionnaires. The questionnaire assessed information on the socio-demographic characteristics of the respondents, knowledge and use of emergency contraceptives. Sources of information on awareness of emergency contraceptives as well as sexuality and pregnancy history were also assessed. The questionnaire was pretested among 20 students at two other departments of Lagos State University which were not selected for the main survey following which necessary modifications were made. The inclusion criteria include selection of respondents who were regular undergraduate students that consented to participate in the study. The exclusion criteria were female students of Lagos State University who were not in college of health or medical sciences related courses, not an health worker on part time basis or had ever worked in a hospital setting before. They were educated on how to fill the questionnaire after verbal consent was obtained.

Data processing and analysis were done using the SPSS version 16 (Chicago, Illinois, USA). Descriptive statistics and odds ratio were used to show associations between target variables and statistical comparison was done using Chi-square test. Results were presented using descriptive statistics, cross-tabulation and logistic regression. $P$-Value $<0.05$ was considered statistically significant at $95 \%$ confidence interval.

\section{Results}

Full responses were obtained from 725 questionnaires which gave a response rate of $90 \%$. Fifty questionnaires were not returned, three had their names written on and were discarded while 27 were not completely filled.

The socio-demographic and academic characteristics of the study population were presented in Table 1 . The mean age of the respondents was 20.9 years with modal range of 20 - 24 years (62.9\%). Participants aged 16 - 24 years accounted for $93.2 \%(676 / 725)$ of the respondents. Most of the respondents were single at $73.1 \%(530 / 725)$ while $16.7 \%$ were married and others (divorcees, cohabiters, separated) constituted remaining 5.2\%. Considering the religion, 69.4\% (503/735) were orthodox Christians, 18.4\% (133/725), were Catholics and only $12.0 \%$ were Muslims. Only $9.9 \%$ (72/725) of the respondents had delivered before. Most of the respondents were in their first year of study (37.1\%) (269/725) while those in the fourth year made up (72/725) constituting the least of the smallest sample of the study population.

The sexual characteristics with various contraceptives used among respondents were shown in Table 2. Three hundred and thirty four respondents $46.1 \%$ 
Table 1. Socio-demography and academic history.

\begin{tabular}{|c|c|c|}
\hline AGE & $\mathrm{NO}$ & $\%$ \\
\hline $16-19$ & 220 & 30.3 \\
\hline $20-24$ & 456 & 62.9 \\
\hline $25-29$ & 27 & 3.7 \\
\hline $30^{+}$ & 15 & 2.1 \\
\hline No response & 7 & 1.0 \\
\hline \multicolumn{3}{|c|}{ MARITAL STATUS } \\
\hline Single & 530 & 73.1 \\
\hline Married & 121 & 16.7 \\
\hline Other & 38 & 5.2 \\
\hline No responses & 36 & 5.0 \\
\hline \multicolumn{3}{|l|}{ RELIGION } \\
\hline Orthodox Xtian & 503 & 69.4 \\
\hline Catholics & 133 & 18.4 \\
\hline Muslims & 87 & 12.0 \\
\hline No responses & 2 & 0.2 \\
\hline \multicolumn{3}{|c|}{ NO OF CHILDREN } \\
\hline None & 584 & 80.6 \\
\hline $1^{+}$ & 72 & 9.9 \\
\hline No responses & 69 & 9.5 \\
\hline \multicolumn{3}{|l|}{ YEAR OF STUDY } \\
\hline 1 & 269 & 37.1 \\
\hline 2 & 185 & 25.5 \\
\hline 3 & 93 & 12.8 \\
\hline 4 & 72 & 9.9 \\
\hline 5 & 77 & 10.6 \\
\hline No responses & 29 & 4.0 \\
\hline
\end{tabular}

Table 2. Sexual and contraceptive history.

\begin{tabular}{ccc}
\hline Ever had sex & No & $\%$ \\
\hline Yes & 334 & 46.1 \\
No & 382 & 52.6 \\
No response & 9 & 1.3 \\
Age at First sexual intercourse $(\boldsymbol{n}=\mathbf{3 3 4})$ & & \\
$<15$ years & 61 & 18.2 \\
$15-19$ years & 254 & 76.0 \\
$20^{+}$years & 19 & 5.8 \\
Mean $=17$ years & & \\
\hline
\end{tabular}




\section{Continued}

Ever used contraception $(n=334)$

Ever used emergency contraceptive $(n=174)$ sexually active

Type of EM contraceptive use (multiple responses allowed)

$\begin{array}{ccc}\text { IUCD } & 18 & 10 \% \\ \text { Postinor } & 48 & 26 \% \\ \text { Mestrogen } & 39 & 22 \% \\ \text { OCPS } & 41 & 23 \% \\ \text { Injection } & 4 & 2 \% \\ \text { Others (Potash + bitter lemon, douching, herbal etc.) } & 30 & 17 \%\end{array}$

(334/725) have had sexual intercourse before. Only 52.1\% (174/334) sexually active respondents have used contraceptives before. Emergency contraceptives accounted for $46.6 \%$ (81/174) of methods used which include Postinor, Oral Contraceptive Pills and Intra-Uterine Contraceptive Devise (IUCD) that were orthodox and conventional 57\% (101/174).

Out of 334 respondents, $18.2 \%$ (61/334) had their coitache (sexual debut) before 15 years while it was $76 \%$ (254/334) in (15 - 19 yrs) group with a mean age of 17 years. About $34.4 \%$ (115/334) of them had been pregnant before with one $65 \%$ (75/115), two $23 \%$ (27/115) and three $10 \%(12 / 115)$ pregnancies respectively. Teenage pregnancy was observed in $87 \%(100 / 105)$ with $80 \%(92 / 115)$ of this being unwanted pregnancy. About sixty-eight percent (63/92) of these unwanted pregnancies were terminated mostly by untrained abortionists in $54 \%$ of cases while $31 \%$ self induced, Table 3 .

Knowledge, attitude towards and utilization of emergency contraceptives among respondents were depicted on Table 4. About 38\% (279/725) respondents) have heard of emergency contraceptives before with postinor and combined oral contraceptive pills accounting for $49 \%$ and intra-uterine contraceptive device (IUCD) for the remaining 10\%. Other unorthodox methods accounted for the remaining EC mentioned. Among the respondents with knowledge of EC, 33.5\% (94/279) had positive attitude towards its use compared to $60 \%$ (167/279) of those with negative attitude. The reasons attributed to negative attitude include the belief that it is sinful to use emergency contraceptives, may cause infertility, birth defect in case of pregnancy, promotion of sexual promiscuity, and loss of confidence among partners.

Also shown in Table 4 were $38.5 \%$ of the total respondents that have ever heard of emergency contraceptives. The main source of Information on Emergency 
Table 3. Pregnancy-related characteristics.

\begin{tabular}{|c|c|c|c|}
\hline \multirow[t]{2}{*}{1} & \multicolumn{3}{|c|}{ Ever been pregnant before $n=334$} \\
\hline & Yes & 155 & 34 \\
\hline & No & 219 & $66 \%$ \\
\hline \multirow[t]{5}{*}{2} & \multicolumn{3}{|c|}{ No of times ever been pregnant $n=115$} \\
\hline & 1 & 75 & $65 \%$ \\
\hline & 2 & 27 & $23 \%$ \\
\hline & 3 & 12 & $10 \%$ \\
\hline & No responses & 1 & $1 \%$ \\
\hline \multirow[t]{4}{*}{3} & \multicolumn{3}{|c|}{ Age at $1^{\text {st }}$ pregnancy $n=115$} \\
\hline & $<15$ & 23 & 20 \\
\hline & $15-19$ & 77 & 67 \\
\hline & $20^{+}$ & 15 & 13 \\
\hline \multirow[t]{3}{*}{4} & \multicolumn{3}{|c|}{ Ever had unwanted pregnancy $n=115$} \\
\hline & Yes & 92 & 80 \\
\hline & No & 23 & 20 \\
\hline \multirow[t]{5}{*}{5} & \multicolumn{3}{|c|}{ Pregnancy outcome of unwanted pregnant $n=92$ (multiple responses) } \\
\hline & Spontaneous abortion & 14 & 15.2 \\
\hline & Induces Abortion & 63 & 68.5 \\
\hline & Delivery & 7 & 7.6 \\
\hline & No Response & 8 & 8.7 \\
\hline \multirow[t]{4}{*}{6} & \multicolumn{3}{|c|}{ No of abortion $n=63$} \\
\hline & 1 & 31 & $49.4 \%$ \\
\hline & 2 & 24 & $38.3 \%$ \\
\hline & $3^{+}$ & 8 & $12.4 \%$ \\
\hline \multirow[t]{4}{*}{7} & \multicolumn{3}{|c|}{ Place of induced abortion $n=63$ (multiple responses) } \\
\hline & Untrained abortionist & 44 & $54 \%$ \\
\hline & Clinic & 38 & $47 \%$ \\
\hline & Self & 25 & $31 \%$ \\
\hline
\end{tabular}

Table 4. Knowledge, attitude towards and practice of EC.

\begin{tabular}{cccc}
\hline $1 \quad$ Ever heard of EC & No & $\%$ \\
\hline Yes & 279 & $38.5 \%$ \\
No & 436 & $60.1 \%$ \\
No response & 10 & $1.3 \%$ \\
2 & & \\
Type of EC known $(\boldsymbol{n}=\mathbf{2 7 9})$ & 72 & $26 \%$ \\
Postinor & 64 & $23 \%$ \\
\hline
\end{tabular}




\begin{tabular}{|c|c|c|c|}
\hline \multicolumn{4}{|c|}{ Continued } \\
\hline & Menstrogen & 62 & $22 \%$ \\
\hline & IUCD & 28 & $10 \%$ \\
\hline & Injection & 6 & $2 \%$ \\
\hline & Others (Potash + bitter, lemon, douching, herbal e.t.c) & 47 & $17 \%$ \\
\hline \multirow[t]{5}{*}{3} & Positive attitude towards EC $(n=279)$ & & \\
\hline & Yes & 94 & $33.5 \%$ \\
\hline & No & 167 & $60 \%$ \\
\hline & Don’t know & 10 & $3.9 \%$ \\
\hline & No response & 8 & $2.6 \%$ \\
\hline \multirow[t]{3}{*}{4} & Ever used EC $(n=279)$ & & \\
\hline & Yes & 81 & $29 \%$ \\
\hline & No & 198 & $71 \%$ \\
\hline \multirow[t]{6}{*}{5} & Source of Information on EC & & \\
\hline & Print Media & 74 & $26.5 \%$ \\
\hline & Electronic Media & 66 & $23.6 \%$ \\
\hline & Family \& Friends & 70 & $25 \%$ \\
\hline & Health Workers* & 42 & $15 \%$ \\
\hline & Others - Teachers, Alternative Practitioners etc & 28 & $10 \%$ \\
\hline
\end{tabular}

Health workers - Doctors, Nurses and Pharmacists.

contraception is the Media (print and electronic) in half (140/279) of the respondents while $25 \%$ (70/279) heard about it from family and friends. Health workers were the source of Information in 15\% (42/279) of the respondents while others (including teachers, Alternative medical practitioners) constituted $10 \%(28 / 279)$.

Majority of the respondents (62.5\%) demonstrated negative attitude towards EC usage. Many of them believe that it is sinful to use emergency contraceptive, may cause infertility, birth defect, could promote promiscuity, lead to loss of confidence among partners and therefore will not recommend it to a friend or relatives, Table 5 .

Logistic regression for variables showed positive predictors were increasing age and year of study, married status, history of childbearing, sexual debut, previous pregnancy, previous contraceptive use as well as knowledge of EC $(P<$ $0.0001)$ while religion and ethnicity were negative predictors of usage $(P>0.05)$ Table 6.

\section{Discussion}

This study showed the perception attitude towards and practice of emergency contraception as well as the sexual behavior of female undergraduates in Lagos. The youths constituted majority of the respondents with predominant age 
Table 5. Attitude of towards emergency contraceptive usage.

\begin{tabular}{|c|c|c|c|c|c|c|c|c|c|c|c|}
\hline & \multicolumn{2}{|c|}{ Strongly Agree } & \multicolumn{2}{|c|}{ Agree } & \multicolumn{2}{|c|}{ Neutral } & \multicolumn{2}{|c|}{ Disagree } & \multicolumn{2}{|c|}{ Strongly Disagree } & \multirow{2}{*}{ Total } \\
\hline & Freq. & $\%$ & Freq. & $\%$ & Freq. & $\%$ & Freq. & $\%$ & Freq. & $\%$ & \\
\hline $\begin{array}{c}\text { EC Use Cause Loss of Confidence } \\
\text { between Partners }\end{array}$ & 301 & $41.517 \%$ & 290 & $40.000 \%$ & 13 & $1.793 \%$ & 110 & $15.172 \%$ & 11 & $1.517 \%$ & 725 \\
\hline $\begin{array}{l}\text { It is a bad idea to avail EC to all } \\
\text { Females }\end{array}$ & 300 & $41.379 \%$ & 222 & $30.621 \%$ & 3 & $0.414 \%$ & 150 & $20.690 \%$ & 50 & $6.897 \%$ & 725 \\
\hline $\begin{array}{l}\text { The Services in Campus/Nearby } \\
\text { Clinic is not convenient to use EC }\end{array}$ & 325 & $44.828 \%$ & 190 & $26.207 \%$ & 10 & $1.379 \%$ & 140 & $19.310 \%$ & 60 & $8.276 \%$ & 725 \\
\hline $\begin{array}{c}\text { It is not a good Idea to use EC after } \\
\text { Unsafe Sexual Intercourse }\end{array}$ & 115 & $15.862 \%$ & 210 & $28.966 \%$ & 20 & $2.759 \%$ & 200 & $27.586 \%$ & 180 & $24.828 \%$ & 725 \\
\hline It is sinful to use EC & 110 & $15.172 \%$ & 215 & $29.655 \%$ & 30 & $4.138 \%$ & 150 & $20.690 \%$ & 200 & $27.586 \%$ & 725 \\
\hline EC Use may cause Infertility & 150 & $20.690 \%$ & 301 & $41.517 \%$ & 24 & $3.310 \%$ & 150 & $20.690 \%$ & 100 & $13.793 \%$ & 725 \\
\hline EC Use may cause Birth Defect & 300 & $41.379 \%$ & 100 & $13.793 \%$ & 25 & $3.448 \%$ & 160 & $22.069 \%$ & 140 & $19.310 \%$ & 725 \\
\hline Use of EC promotes PROMISCUITY & 200 & $27.586 \%$ & 295 & $40.690 \%$ & 5 & $0.690 \%$ & 125 & $17.241 \%$ & 100 & $13.793 \%$ & 725 \\
\hline Available ECP are ineffective to prove & 234 & $32.276 \%$ & 176 & $24.276 \%$ & 15 & $2.069 \%$ & 150 & $20.690 \%$ & 150 & $20.690 \%$ & 725 \\
\hline \multirow[t]{4}{*}{ Total } & & 32.207 & & 30.35 & & 2.14 & & 19.8 & & 15.24 & \\
\hline & & Negative & & & & & & Positive & & & \\
\hline & & Attitude & & & & & & Attitude & & & \\
\hline & & & 62.557 & & & & & & 35.04 & & \\
\hline
\end{tabular}

Table 6. Predictors of emergency contraceptive usage.

\begin{tabular}{|c|c|c|c|c|c|c|c|c|c|}
\hline \multirow{3}{*}{ Characteristics } & \multirow{3}{*}{ Total } & \multicolumn{4}{|c|}{ Use of EC } & \multirow{3}{*}{ COR } & \multirow{3}{*}{ AOR } & \multirow{3}{*}{ Chi-Square } & \multirow{3}{*}{$P$-Value } \\
\hline & & \multicolumn{2}{|c|}{ Yes } & \multicolumn{2}{|c|}{ No } & & & & \\
\hline & & no & $\%$ & no & $\%$ & & & & \\
\hline \multicolumn{10}{|c|}{ Age (Years) } \\
\hline $15-19$ & 220 & 8 & $4 \%$ & 212 & $96 \%$ & 1 & 1 & & \\
\hline $20+$ & 505 & 130 & $26 \%$ & 375 & $74 \%$ & $9.05(2.734-33.729)$ & $6.973(2.374-24.453)$ & 19.421 & 0.00 \\
\hline \multicolumn{10}{|c|}{ Year of Study } \\
\hline 1 & 289 & 22 & $8 \%$ & 247 & $85 \%$ & 1 & 1 & & \\
\hline 2 & 185 & 27 & $15 \%$ & 158 & $85 \%$ & $7.564(3.140-18.820)$ & $4.938(2.412-10.965)$ & 27.855 & 0.00 \\
\hline $3+$ & 271 & 146 & $54 \%$ & 125 & $46 \%$ & $13.212(5.505-32.789)$ & $6.642(3.357-14.390)$ & 48.863 & 0.00 \\
\hline \multicolumn{10}{|c|}{ Marital Status } \\
\hline Never Married & 604 & 13 & $2 \%$ & 591 & $98 \%$ & 1 & 1 & & \\
\hline Married & 121 & 35 & $29 \%$ & 86 & $71 \%$ & $15.599(3.723-84.826)$ & $11.657(3.118-60.661)$ & 24.208 & 0.00 \\
\hline \multicolumn{10}{|c|}{ No of Children } \\
\hline None & 584 & 16 & $3 \%$ & 568 & $97 \%$ & 1 & 1 & & \\
\hline One and above & 141 & 36 & $26 \%$ & 105 & $74 \%$ & $12.012(3.109-56.670)$ & $9.259(2.684-41.612)$ & 20.839 & 0.00 \\
\hline
\end{tabular}




\section{Continued}

\begin{tabular}{|c|c|c|c|c|c|c|c|c|c|}
\hline \multicolumn{10}{|c|}{ Age at First Intercourse } \\
\hline$<15$ years & 61 & 1 & $2 \%$ & 60 & $98 \%$ & 1 & 1 & & \\
\hline $15-19$ years & 254 & 18 & $7 \%$ & 236 & $93 \%$ & $19.143(4.485-108.320)$ & $13.682(3.604-74.117)$ & 28.741 & 0.00 \\
\hline 20 years+ & 19 & 1 & $5 \%$ & 18 & $95 \%$ & $11.114(2.532-64.228)$ & $9.091(2.295-50.483)$ & 16.054 & 0.00 \\
\hline \multicolumn{10}{|c|}{ Religion } \\
\hline Christianity & 638 & 20 & $3 \%$ & 618 & $97 \%$ & 1 & 1 & & \\
\hline Muslim & 87 & 7 & $8 \%$ & 80 & $92 \%$ & $3.060(0.689-15.815)$ & $2.893(0.703-14.306)$ & 2.726 & $0.77^{*}$ \\
\hline \multicolumn{10}{|l|}{ Others } \\
\hline \multicolumn{10}{|c|}{ Ethnicity } \\
\hline Yoruba & 385 & 8 & $2 \%$ & 377 & $98 \%$ & 1 & 1 & & \\
\hline Igbo & 183 & 6 & $3 \%$ & 177 & $97 \%$ & $1.725(0.244-14.551)$ & $1.700(0.253-13.888)$ & 0.373 & $0.75^{*}$ \\
\hline Hausa & 74 & 4 & $5 \%$ & 70 & $95 \%$ & $2.633(0.442-20.044)$ & $2.550(0.454-18.780)$ & 0.236 & $0.237^{\star}$ \\
\hline \multicolumn{10}{|c|}{ Ever Being Pregnant } \\
\hline No & 115 & 33 & $29 \%$ & 82 & $71 \%$ & 1 & 1 & & \\
\hline Yes & 219 & 77 & $35 \%$ & 211 & $96 \%$ & $0.089(0.023-0.2980)$ & $0.121(0.033-0.359)$ & 23.952 & 0.00 \\
\hline \multicolumn{10}{|c|}{ Prior Regular Contraceptive Use } \\
\hline No & 443 & 11 & $2 \%$ & 432 & $98 \%$ & 1 & 1 & & \\
\hline Yes & 282 & 79 & $28 \%$ & 203 & $72 \%$ & $0.188(0.069-0.488)$ & $0.243(0.098-0.551)$ & 15.636 & 0.00 \\
\hline \multicolumn{10}{|c|}{ Knowledge } \\
\hline Poor Knowledge & 220 & 17 & $8 \%$ & 203 & $92 \%$ & 1 & 1 & & \\
\hline Good Knowledge & 191 & 62 & $32 \%$ & 129 & $68 \%$ & $5.640(2.288-14.368)$ & $4.141(1.947-9.517)$ & 18.723 & 0.00 \\
\hline \multicolumn{10}{|c|}{ Attitude } \\
\hline Negative & 227 & 23 & $10 \%$ & 204 & $90 \%$ & 1 & 1 & & \\
\hline Positive & 127 & 34 & $27 \%$ & 93 & $73 \%$ & $3.275(1.407-7.771)$ & $2.663(1.321-5.643)$ & 9.36 & 0.00 \\
\hline
\end{tabular}

ranging from 16 to 24 years accounting for $93.2 \%$ which was comparable to $89.6 \%$ reported by Ibekwe et al. [15]. This is the demography most at risk of unprotected sexual intercourse and the attendant risk of unwanted pregnant and subsequently unsafe abortion [16] [17]. The 73.1\% single subjects found in this study is less that $87.2 \%$ and $90.7 \%$ observed among similar subjects in Anambra [15] and Abakaliki [18] respectively.

Respondents who were sexually exposed accounted for $46.1 \%$ which was lower than the $57 \%, 77 \%, 86 \%$ and $87 \%$ observed among similar subjects in S/Africa [19], Benin [20], Ibadan [13] and Abakalik [18] but higher than 34.5\% obtained in Lagos [21]. The mean age of 17 years at coitache (sexual debut) in this study is lower than the 22 years reported by Obuehi et al., [21], also in the University of Lagos, but higher than the 16-year mean from the study by Adeneye et al. [22], in which it was observed that many of their respondents got pregnant before the age of 20 years. Unfortunately, adolescents incorrectly start sexual activity before 
practicing contraception. They often do not plan their first intercourse, or may have infrequent intercourse with no contraceptive protection. Curiosity, peer pressure and difficult situations may lure adolescents into early, high risk sexual intercourse [23]. In Nigeria, it has been observed that unintended sexual intercourse is the leading cause of unintended pregnancy and induced abortions [24]. Steinberg and co-workers observed that adolescents who engaged in effective communication with their parents on sexuality issues are more likely than others to delay sexual intercourse [25].

In this study, $52.1 \%$ of sexually exposed respondents have ever used contraceptive before in contrast to $34.7 \%$ of the respondents among similar subjects in Ibadan [26]. It has also been observed that in spite of the high premarital sexual activity among the adolescents, their use of contraceptive is very low [27]. It is estimated that more than $60 \%$ of women with unintended pregnancies were not using any form of contraceptive [28] [29]. Some workers have observed that despite the availability of these services, their use by the youths is still poor probably due to lack of adequate information about efficacy of the methods, fear of side effects, shame, negative cultural beliefs and the judgmental attitude of service providers [30].

It is noteworthy that $82 \%$ of the respondents in this study that had ever been pregnant were not married. Sixty-three percent of pregnancies in this study were unwanted with single and married respondents accounting for $73 \%$ and $10 \%$ respectively. These pregnancies, in $54 \%$ of the cases, were terminated mostly by untrained abortionists, while $31 \%$ were self-induced using other unconventional methods. This figure was higher than 43.6\%, from Ghana [31], $31.1 \%$ in southwestern Nigeria [27], 22.1\% in Calabar [23] and the National average [32] of $8 \%$. Some workers in their community survey observed that married women also experienced unwanted pregnancy, as they constituted $34.8 \%$ and $63.2 \%$ of abortion seekers in two studies respectively from southwestern Nigeria [27] [33]. The consequences of these clandestine abortions are grave and can be life-threatening, often leading to maternal death. Abortions account for $20 \%-40 \%$ of maternal deaths in Nigeria [7]. It has been reported that some women use abortion as a means of child spacing instead of contraception [34]. This may be as a result of low contraceptive uptake rates despite reported high contraceptive awareness and enlightenment drives [16] [34].

Emergency contraceptives are the only form of contraceptives that can be used after unprotected sexual intercourse offering a second chance to prevent unwanted pregnancy [22]. About 38\% of the respondents in this study had prior awareness of emergency contraceptives, and only $29 \%$ had ever used them. This awareness was less than $86 \%$ in USA [35], 84\% in Ethiopia [36], 56\% in Calabar [37], 43.2\% in Ghana [31] but similar to 38.1\% reported in Abakaliki [18]. The concomitant use of EC by $29 \%$ among our respondents was similar to $30.7 \%$ reported by Ebuehi et al. [21] but higher than $11.5 \%$ and $10 \%$ among similar sub- 
jects in southeastern Nigeria [15] [18].

In this study, postinor was the most widely known EC (26\%) followed by COCPs (23\%), IUCD (10\%) and other unconventional methods including menstrogen (22\%), douching, herbal medicaments, potash with bitter lemon drink and the likes, accounting for the remaining methods. The $59 \%$ subjects that correctly identified conventional EC method in this study was higher than $26.4 \%$ and $36.3 \%$ reported by other workers among similar subjects [15] [21]. Major identified EC methods in this study were less than $45 \%$ postinor and $33 \%$ OCP reported by Nworah and colleagues [18]. Menstrogen, an oestrogen only pill used in the treatment of conditions related to low hormonal levels was used as emergency contraceptive in $22 \%$ respondents in contrast to $0.6 \%$ of similar subjects in other reports [18]. Its effectiveness as an emergency contraceptive requires its use in high doses [21].

The main sources of information on EC were mass media (print and electronic) in half of subjects, followed by $25 \%$ who got their information from peers (friends), 15\% from health workers and other sources accounting for the remaining. This was contrary to findings of other workers that reported $20.6 \%$ \& $26 \%$ for media and $32.9 \% \& 31.4 \%$ from friends respectively [15] [18]. Obuehi 2006 reported that friends accounted for $64.9 \%$ source of information on EC [21]. The knowledge of emergency contraceptives was significantly higher among the senior students as compared to their juniors. This finding is very similar and consistent with studies in Ethiopia, Ghana, Cameroon and even in France where increasing age and year of study were find to influence the knowledge about Emergency contraception [38]. This could be due to younger subjects having less information about the proper use of EC but seems to get more Information as they advance in their studies. Raising awareness about the methods and making it both easily available and accessible will improve its use because emergency contraception are financially, psychologically and physically less burdensome than abortion.

Most respondents (62.6\%) demonstrated strong negative attitudes towards emergency contraceptive, which was consistent with findings in other studies [14] [39], but however contrasted with findings in Cameroon [40]. The reasons attributed to negative attitude include the belief that it is sinful to use emergency contraceptives, may cause infertility, birth defect in case of pregnancy, promotion of sexual promiscuity, and loss of confidence among partners. Some workers have observed that lack of knowledge of EC and fear of side effects were the most frequently cited reason for not using them among similar subjects [41] [42].

Positive attitude towards EC in this study was significantly higher among orthodox Christians, Muslims, while Catholic and Protestants demonstrated negative attitude to emergency Contraception. Similarly, senior students and married people shows positive attitude to emergency contraception. About $27.6 \%$ of our respondents believed that emergency Contraceptives are very important and 
should be made available to all females while $29.5 \%$ were willing to recommend emergency contraceptives to friends. Feleke et al. [42] also posited that women's age of 20 - 24 years, urban residence, being single, being knowledgeable on emergency contraception, and having favorable attitude towards emergency contraception were significantly associated factors with the utilization of emergency contraceptives.

Positive predictors of EC usage in this study include increasing age and year of study, married status, previous childbirth, sexual debut, previous pregnancy, previous contraceptive use as well as knowledge of EC while religion and ethnicity were poor predictors. Our findings were similar to that of other workers where lack of knowledge, fear of being seen by others, and inconvenient service delivery were pointed out as the main reasons for not using emergency contraceptives [39] [41] [42]. Previous use of contraceptives, being married and age of 20 years and above were significant predictors for the use of emergency contraceptives, while poor knowledge of emergency contraceptive was a significant predictor of non-use of emergency contraceptives [38] [41] [43] [44].

This study was based on self-reported information which may be subjective to reporting errors, missed values and bias. Since the study touches on sensitive issues, the possibility of underestimation cannot be excluded, even though the respondents were anonymous. Nevertheless, it provides an insight into the sexuality, awareness and usage of EC as well as related predictors of its usage amongst female undergraduates in the Lagos State University.

\section{Conclusions}

In conclusion, the awareness of emergency contraceptive is low while its usage is even far lower, yet high rate of sexual activity and unwanted pregnancies have been reported. It is strongly recommended that information about contraceptives should be introduced in schools, as early as secondary schools and also in general studies courses in tertiary institutions. Parents and care givers should be bold and confident enough to discuss issues relating to sex, contraceptives, sexually transmitted infections and family planning with the adolescents instead of allowing them to source for information from the internet or from peer groups who may not be knowledgeable enough on such matters.

Stakeholders should ensure provision of youth-friendly sexual and reproductive health services designed to respond to and meet the health needs of these apparently sexually active young people as reflected in the Nigeria's Policy on Population for Development [45]. It is expected that this will contribute to meeting a target of the Sustainable Development Goal (SDG) 3 which aims at ensuring universal access to sexual and reproductive healthcare services, information, education, including family planning [46].

\section{Conflicts of Interest}

The authors declare no conflicts of interest regarding the publication of this paper. 


\section{References}

[1] Adinma, B.D. (2002) An Overview of the Global Policy Census on Women's Sexual and Reproductive Rights. The Nigerian Perspective. Tropical Journal of Obstetrics and Gynaecology, 19, 9-12.

[2] Henshaw, S.K., Singh, S., Oye-Adeniran, B.A., Adewole, I.F., Iwere, N. and Cuca, Y.P. (1998) The Incidence of Induced Abortion in Nigeria. International Family Planning Perspectives, 24, 156-164. https://doi.org/10.2307/2991973

[3] World Health Organization (WHO) (2011) Unsafe Abortion: Global and Regional Estimates of the Incidence of Unsafe Abortion and Associated Mortality in 2008. Sixth Edition, WHO, Geneva.

[4] Singh, S. (2006) Hospital Admissions Resulting from Unsafe Abortion: Estimates from 13 Developing Countries. The Lancet, 368, 1887-1892. https://doi.org/10.1016/S0140-6736(06)69778-X

[5] Singh, S., et al. (2006) Unintended Pregnancy and Induced abortion in Uganda: Causes and Consequences. Guttmacher Institute, New York.

[6] Aziken, M.E., Okonta, P.I. and Ande, A.B.A. (2003) Knowledge and Perception of Emergency Contraception among Female Nigerian Undergraduates. International Family Planning Perspectives, 29, 84-87. https://doi.org/10.2307/3181062

[7] Abiodun, O.M. and Balogun, O.R. (2009) Sexual Activity and Contraceptive Use among Young Female Students of Tertiary Educational Institutions in Ilorin, Nigeria. Contraception, 79, 146-149. https://doi.org/10.1016/j.contraception.2008.08.002

[8] Alio, A.P., Nana, P.N. and Salihu, H.M. (2009) Spousal Violence and Potentially Preventable Single and Recurrent Spontaneous Fetal Loss in an African Setting: Cross-Sectional Study. The Lancet, 373, 318-324. https://doi.org/10.1016/S0140-6736(09)60096-9

[9] Emenike, E., Lawoko, S. and Dalal, K. (2008) Intimate Partner Violence and Reproductive Health Women in Kenya. International Nursing Review, 55, 97-102. https://doi.org/10.1111/j.1466-7657.2007.00580.x

[10] Ahmed, F.H., et al. (2005) Reducing Unintended Pregnancy and Unsafe Abortion in Uganda. Research in Brief, the Alan Guttmacher Institute (AGI), New York, No. 1.

[11] Haggai, D.P.N. (2003) Emergency Contraception: The Journey So Far. British Journal of Obstetrics and Gynaecology, 110, 339-345. https://doi.org/10.1046/j.1471-0528.2003.t01-1-02005.x

[12] Fayemi, M.M., Oduola, O.L., Ogbuji, Q.C., Osinowo, K.A., Oyewo, A.E. and Osiberu, O.M. (2010) Knowledge of Emergency Contraception and Dispensing Practices of PMV in South West Nigeria. Journal of Public Health Policy, 31, 281-294. https://doi.org/10.1057/jphp.2010.14

[13] Bello, F.A., Olayemi, O., Fawole, A.O., Ogunbode, O.O., Sobukunola, T., Adesina, O.A., et al. (2009) Perception and Practice of Emergency Contraception among Female Undergraduate of University of Ibadan, Nigeria. Journal of Reproduction and Contraception, 20, 113-121. https://doi.org/10.1016/S1001-7844(09)60015-8

[14] Akani, C.E., Eyindah, C.E. and Babatunde (2008) Emergency Contraception; Knowledge and Perception of Female Undergraduates in Niger Delta of Nigeria. Ghana Medical Journal, 42, 68-70. https://doi.org/10.4314/gmj.v42i2.43598

[15] Ibekwe, P.C. and Obuna, J.A. (2010) Awareness and Practice of Emergency Contraception among University Students in Abakaliki, Southeast Nigeria. Nigerian Journal of Clinical Practice, 13, 20-23. 
[16] Oye-Adeniran, B.A., Adewole, I.F., Umoh, A.V., Ekanem, E.E., Gbadegesin, A. and Iwere, N. (2004) Community-Based Survey of Unwanted Pregnancy in Southwestern Nigeria. African Journal of Reproductive Health, 8, 103-115. https://doi.org/10.2307/3583397

[17] Okonofua, F.E., Odimegwu, C., Ajabor, H., Daru, P.H. and Johnson, A. (1999) Assesing the Prevalence and Determinants of Unwanted Pregnancies and Induced Abortion in Nigeria. Studies in Family Planning, 30, 67-77. https://doi.org/10.1111/j.1728-4465.1999.00067.x

[18] Nworah, J.A., Mbamara, S.U., Ugboaja, J.O., Ogelle, M.O. and Akabuike, J.C. (2010) Knowledge, Attitude and Practice of Emergency Contraception among Students in Tertiary Schools in Anambra State Southeast Nigeria. Internation Journal of Medicine and Medical Sciences, 2, 1-4.

[19] Robert, G., Moudley, J. and Esterhoizen, T. (2004) Emergency Contraception; Knowledge and Practice of Tertiary Students in Durban. South African Journal of Obstetrics and Gynaecology, 24, 441-445. https://doi.org/10.1080/01443610410001685619

[20] Unuigbe, I.E. and Ogbeide, O. (1999) Sexual Bahaviour and Perception of AIDS among Adolescent Girls in Benin City, Nigeria. African Journal of Reproductive Health, 3, 39-44. https://doi.org/10.2307/3583227

[21] Ebuehi, O.M., Ekanem, E.E. and Ebuehi, O.A.T. (2006) Knowledge and Practice of Emergency Contraception among Female Undergraduates in the University of Lagos, Nigeria. East Africa Medical Journal, 83, 90-95. https://doi.org/10.4314/eamj.v83i3.9403

[22] Adeneye, A.K., Erinosho, O.A., Adeneye, A.A. and Obasi, C.C. (2017) Factors Associated with Unplanned Pregnancy among Unmarried Adolescents in Selected Communities of Ogun State, Nigeria. Archives Preventive Medicine, 2, 1-9. https://doi.org/10.17352/apm.000005

[23] Ndifon, W.O., Ogaji, D.S.T. and Etuk, S.J. (2006) Sexuality, Contraception and Unintended Pregnancy among Female Student Nurses in Calabar, Nigeria. Benin Journal of Postgrad Medicine, 8, 12-21. https://doi.org/10.4314/bjpm.v8i1.47359

[24] Ezebialu, I.U. and Eke, A.C. (2013) Emergency Contraception in Female Students. Annals of Medical and Health Science Research, 3, 541-545. https://doi.org/10.4103/2141-9248.122092

[25] Steinberg, L. (2001) We Know Some Things: Parent-Adolescent Relationships in Retrospect and Prospect. Journal Research in Adolescence, 11, 1-19. https://doi.org/10.1111/1532-7795.00001

[26] Arowojolu, A.O., Ilesanmi, A.O., Roberts, O.A. and Okunola, M.A. (2002) Sexuality, Contraceptive Choice and AIDS Awareness among Nigerian Undergraduates. African Journal of Reproductive Health, 6, 60-70. https://doi.org/10.2307/3583131

[27] Lamina, M.A. (2015) Prevalence and Determinants of Unintended Pregnancy among Women in South-Western Nigeria. Ghana Medical Journal, 49, 187-194. https://doi.org/10.4314/gmj.v49i3.10

[28] Osaro, B.O., Tobin-West, C.I. and Mezie-Okoye, M.M. (2017) Knowledge of Modern Contraceptives and Their Uses among Rural Women of Childbearing Age in Rivers State Nigeria. Annals of Tropical Medicine and Public Health, 10, 1043-1048. https://doi.org/10.4103/ATMPH.ATMPH 76216

[29] National Population Commission (NPC) [Nigeria] and ICF Macro (2009) Nigeria Demographic and Health Survey 2008. National Population Commission and ICF 
Macro, Abuja, Nigeria.

[30] Odujurin, O.M.T. (1991) Sexual Activity, Contraceptive Practice and Abortion among Adolescents in Lagos, Nigeria. International Journal of Gynecology \& Obstetrics, 34, 360-361. https://doi.org/10.1016/0020-7292(91)90605-5

[31] Geelheod, D., Nayembil, D., Asare, K., Van Leeuwen, J.H. and Van Roosmalen, J. (2002) Gender and Unwanted Pregnancy: A Community-Based Study in Rural Ghana. Journal of Obstetrics and Gynaecology, 23, 249-255. https://doi.org/10.3109/01674820209074679

[32] Okonofua, F.E. (2002) Unwanted Pregnancy, Unsafe Abortion and the Law in Nigeria. Tropical Journal of Obstetrics and Gynaecology, 19, 515-517.

[33] Oye-Adeniran, B.A., Adewole, I.F., Odeyemi, K.A., Ekanem, E.E. and Umoh, A.V. (2005) Contraceptive Prevalence among Young Women in Nigeria. Journal of $O b$ stetrics and Gynaecology, 25, 182-185. https://doi.org/10.1080/01443610500041156

[34] Monjok, E., Smesny, A. and Essien, E.J. (2010) Contraceptive Practices in Nigeria: Literature Review and Recommendation for Future Policy Decisions. Open Access Journal Contraception, 1, 9-22. https://doi.org/10.2147/OAJC.S9281

[35] Kang, H.S. and Moneyham, L. (2008) Use of Emergency Contraceptive Pills and Condoms by College Students: A Survey. International Journal of Nursing Studies, 45, 775-783. https://doi.org/10.1016/j.ijnurstu.2007.01.008

[36] Ahmed, F.A., Moussa, K.M. and Petterson, K.O. (2012) Assessing Knowledge, Attitude, and Practice of Emergency Contraception: A Cross-Sectional Study among Ethiopian Undergraduate Female Students. BMC Public Health, 12, Article No. 110. https://doi.org/10.1186/1471-2458-12-110

[37] Abeshi, S.E., Ago, B.U., Njoku, C.O. and Emechebe, C.I. (2017) Knowledge, Practice and Perception of Contraception by Literate Adolescents in Calabar, Nigeria. European Journal of Biology and Medical Science Research, 5, 1-6.

[38] Olabode, K.O., Bashir, A.M. and Hilary, Z. (2015) Emergency Contraceptives Use among Female Students at Ahmadu Bello University, Zaria, Kaduna State. The Online Journal of New Horizons in Education, 5, 41-48.

[39] Nibabe, W.T. and Mgutshini, T. (2014) Emergency Contraception amongst Female College Students-Knowledge, Attitude and Practice. African Journal Primary Health Care \& Family Medicine, 6, a538. https://doi.org/10.4102/phcfm.v6i1.538

[40] Kongnyuy, E.J., Ngassa, P., Fomulu, N., Wiysonge, C.S., Luc Kouam, L. and Doh, A.S. (2007) A Survey of Knowledge, Attitudes and Practice of Emergency Contraception among University Students in Cameroon. BMC Emergency Medicine, 7, Article No. 7. https://doi.org/10.1186/1471-227X-7-7

[41] Abad, F.N.S., Ahmad, Z., Juni, M.H. and Rahman, A.H. (2011) Emergency Contraception Practice and Its Related Factors in a Sample of Malaysian Women. European Journal of Social Sciences, 20, 513-522.

[42] Feleke, A.E., Nigussie, T.S. and Debele, T.Z. (2019) Utilization and Associated Factors of Emergency Contraception among Women Seeking Abortion Services in Health Institutions of Dessie Town, North East Ethiopia, 2018. BMC Research Notes, 12, Article No. 684. https://doi.org/10.1186/s13104-019-4707-0

[43] Tilahun, F.D., Assefa, T. and Belachew, T. (2011) Predictors of Emergency Contraceptive Use among Regular Female Students at Adama University, Central Ethiopia. Pan African Medical Journal, 7, 16. https://doi.org/10.4314/pamj.v7i1.69126

[44] Makola, L., Mlangeni, L., Mabaso, M., Chibi, B., Sokhela, Z., Silimfe, Z., et al. (2019) 
Predictors of Contraceptive Use among Adolescent Girls and Young Women (AGYW) Aged 15 to 24 Years in South Africa: Results from the 2012 National Population-Based Household Survey. BMC Women's Health, 19, 158.

https://doi.org/10.1186/s12905-019-0861-8

[45] National Population Commission (NPC) [Nigeria] and ICF International (2014) Nigeria Demographic and Health Survey 2013. NPC and ICF International, Abuja, and Rockville.

[46] Murray, C.J.L. and Phil, D. (2015) Shifting to Sustainable Development Goals-Implications for Global Health. New England Journal of Medicine, 373, 1390-1393. https://doi.org/10.1056/NEJMp1510082 


\section{Appendix A}

\section{Questionnaire}

Preamble

We are conducting a study on sexuality and practice of emergency contraception among female undergraduates. We assure you that all your responses and result of this study will be kept strictly confidential and will be used for medical purpose only. We will appreciate it if you fill the questionnaire sincerely to the best of your knowledge.

Thank you for the anticipated cooperation.
A) BIODATA
1) Age (years)
2) Parity
3) Religion
a) Christian
b) Islam
c) Traditionalist
d) Others, specify .....

4) Year of Study (Level)
a) $100 \mathrm{~L}$
b) $200 \mathrm{~L}$
c) $300 \mathrm{~L}$
d) $400 \mathrm{~L}$
e) $>500 \mathrm{~L}$

5) Tribe:
a) Yoruba
b) Igbo
c) Hausa
d) Others, specify

6) Marital Status
a) Single
b) Married
c) Separated
d) Divorce

\section{B) SEXUAL AND REPRODUCTIVE HISTORY}

1) Ever had sexual intercourse before? a) Yes b) No

2) If Yes, at what age (in years) was the first encounter?
3) Have ever been pregnant before?
a) Yes
b) No

a) If yes, how many times?

b) What was/were the outcome? i) Miscarriage; ii) abortion; iii) Delivery

bi) How many deliveries have you had?

bii) If Miscarriage, any complications like: a) bleeding; b) infection; c) Need for further evacuation? d) Other, specify.....

C) KNOWLEDGE AND USAGE OF EMERGENCY CONTRACEPTION KNOWLEDGE:

1) Have you heard of emergency contraception before? a) Yes; b) No

2) If yes, what is the source? a) Health worker; b) Print/Electronic Media; c) School teacher; d) friend/relatives; e) Others, specify.

3) What type of emergency contraception do you know? a) IUCD; b) Postinor; c) Oral Contraceptives Pills; d) Menstrogen; e) Quinine; f) Potash; g) Others, specify

4) Where can one get emergency contraception? a) Pharmacy; b) Chemist; c) Health centre; d) Drug store; e) Nurse; f) Doctors; g) Herbalist; h) Others, specify.

5) How long after intercourse can emergency contraception be taken to be effective? a) Within 5 days; b) Within 3 dyas; c) Within 24 hours; e) After missed period; f) during menses; g) I Don't know; h) others, specify 
6) How effective do you think emergency contraception is in preventing pregnancy? a) Very effective; b) moderately effective; c) minimally effective; d) Not effective

7) Is emergency contraception a method of abortion a) Yes; b) No

\section{D) ATTITUDE}

1) Will you recommend emergency contraception to a friend or relative?

a) Strongly agree; b) agree; c) Neutral; d) disagree; e) Strongly disagree

2) Emergency contraception causes loss of confidence in partner?

a) Strongly agree; b) agree; c) Neutral; d) disagree; e) Strongly disagree

3) It is a bad idea to avail emergency contraceptive use to all females?

a) Strongly agree; b) agree; c) Neutral; d) disagree; e) Strongly disagree

4) The services on campus/nearby clinic are not convenient to use emergency contraceptives?

a) Strongly agree; b) agree; c) Neutral; d) disagree; e) Strongly disagree

5) It is a bad idea to use emergency contraceptives after unprotected intercourse?

a) Strongly agree; b) agree; c) Neutral; d) disagree; e) Strongly disagree

6) It is sinful to use emergency contraceptives?

a) Strongly agree; b) agree; c) Neutral; d) disagree; e) Strongly disagree

7) Emergency contraceptives use may cause infertility?

a) Strongly agree; b) agree; c) Neutral; d) disagree; e) Strongly disagree

8) Emergency contraceptives use may cause birth defect? a) Strongly agree; b) agree; c) Neutral; d) disagree; e) Strongly disagree

9) Emergency contraceptives use promotes sexual promiscuity? a) Strongly agree; b) agree; c) Neutral; d) disagree; e) Strongly disagree

10) Emergency contraceptives are ineffective in preventing pregnancy

a) Strongly agree; b) agree; c) Neutral; d) disagree; e) Strongly disagree

E) PRACTICE

1) Have you ever used any contraception before? a) Yes; b) No

ai) If Yes, what type have you used before? a) IUCD; b) Postinor; c) Oral Contraceptives Pills; d) Menstrogen; e) Quinine; f) Potash; g) Others, specify.........

2) How often do you use the method?

a) always; b) sometimes; c) Occasionally; d) Never

3) What is your reason for using emergency contraceptives?

a) Rape; b) Unprotected intercourse; c) Condom breakage; d) Missed Pill

4) If you are not using any contraception at all or after occasional intercourse, Why?

a) I am looking for pregnancy; b) My menstruation has stopped; c) Usage can lead to infection; d) Others, Specify 